LA W RENCE LIVERM ORE NATION AL LABORATORY
National Ignition Campaign (NIC) Precision Tuning Series Shock Timing Experiments

H. F. Robey, P. M. Celliers

August 9, 2011 
This document was prepared as an account of work sponsored by an agency of the United States government. Neither the United States government nor Lawrence Livermore National Security, LLC, nor any of their employees makes any warranty, expressed or implied, or assumes any legal liability or responsibility for the accuracy, completeness, or usefulness of any information, apparatus, product, or process disclosed, or represents that its use would not infringe privately owned rights. Reference herein to any specific commercial product, process, or service by trade name, trademark, manufacturer, or otherwise does not necessarily constitute or imply its endorsement, recommendation, or favoring by the United States government or Lawrence Livermore National Security, LLC. The views and opinions of authors expressed herein do not necessarily state or reflect those of the United States government or Lawrence Livermore National Security, LLC, and shall not be used for advertising or product endorsement purposes.

This work performed under the auspices of the U.S. Department of Energy by Lawrence Livermore National Laboratory under Contract DE-AC52-07NA27344. 


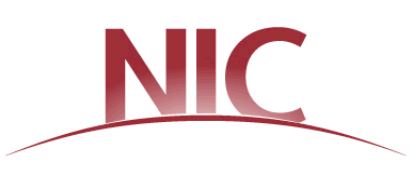

NIF-0117490

\title{
National Ignition Campaign (NIC) Precision Tuning Series: Shock Timing Experiments
}

\author{
Harry Robey and Peter Celliers
}

A series of precision shock timing experiments have been performed on NIF. These experiments continue to adjust the laser pulse shape and employ the adjusted cone fraction (CF) in the picket $\left(1^{\text {st }} 2 \mathrm{~ns}\right.$ of the laser pulse) as determined from the re-emit experiment series. The NIF ignition laser pulse is precisely shaped and consists of a series of four impulses, which drive a corresponding series of shock waves of increasing strength to accelerate and compress the capsule ablator and fuel layer. To optimize the implosion, we tune not only the strength (or power) but also, to sub-nanosecond accuracy, the timing of the shock waves. In a well-tuned implosion, the shock waves work together to compress and heat the fuel. For the shock timing experiments, a re-entrant cone is inserted through both the hohlraum wall and the capsule ablator allowing a direct optical view of the propagating shocks in the capsule interior using the VISAR (Velocity Interferometer System for Any Reflector) diagnostic from outside the hohlraum. To emulate the DT ice of an ignition capsule, the inside of the cone and the capsule are filled with liquid deuterium. A photo of the target is shown in Figure 1.

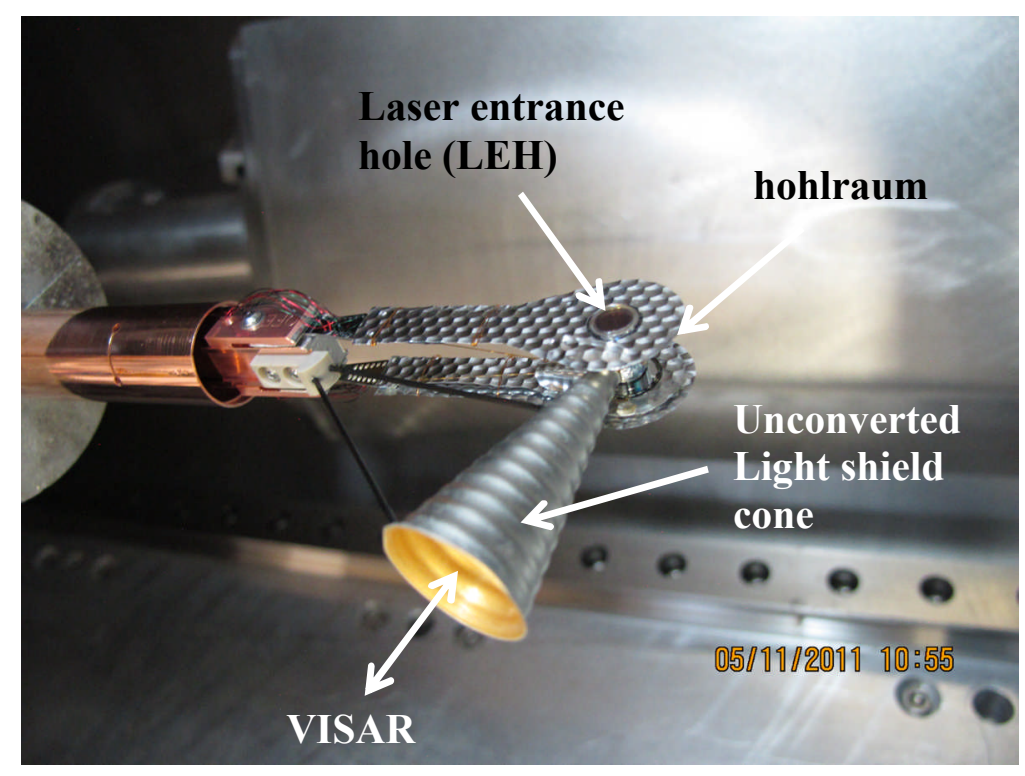

Figure 1. Photograph of a shock-timing target installed on the I-TIC. The reentrant cone, which penetrates the hohlraum, cannot be seen in this photo since it is located inside the larger unconverted light shield cone, which protects the target from unconverted light.

Five shock-timing experiments were conducted in this campaign. Previous NIC shock timing experiments were limited to diagnosis of only the first three pulses, with additional shots 
employing a slightly modified target used to time the $4^{\text {th }}$ pulse. In this campaign, the fourth pulse was added for the first time allowing a more complete and integrated characterization of the shock timing. The laser pulse shape for the initial shots used an increased delay between the $2^{\text {nd }}, 3^{\text {rd }}$, and $4^{\text {th }}$ pulses in order to provide sufficient duration of each shock for VISAR observation. Throughout the campaign, the $4^{\text {th }}$ pulse was truncated in time compared to the point design ignition pulse (Rev $5.1 \mathrm{draft} 3$ ), as the shock timing is completely determined by the time the laser pulse reaches peak power. This saves laser energy and minimizes debris accumulation on the optics. On subsequent shots, the power and timing of various parts of the pulse were adjusted to set the strength and timing of the shocks to match the Rev5.1 goal. Figure 2 shows a plot of the pulse shapes used for the 5 experiments in this tuning series, and Table 1 lists a summary of the changes that were made to each part of the laser pulse from shot-to-shot. For all shots, the delivered laser pulse matched the requested pulse shape to very high precision. The black curves in Figure 2 show the requested pulse shape. Deviations between the requested and delivered pulse shapes can only be seen at the low-power troughs following the $2^{\text {nd }}$ and $3^{\text {rd }}$ pulses.

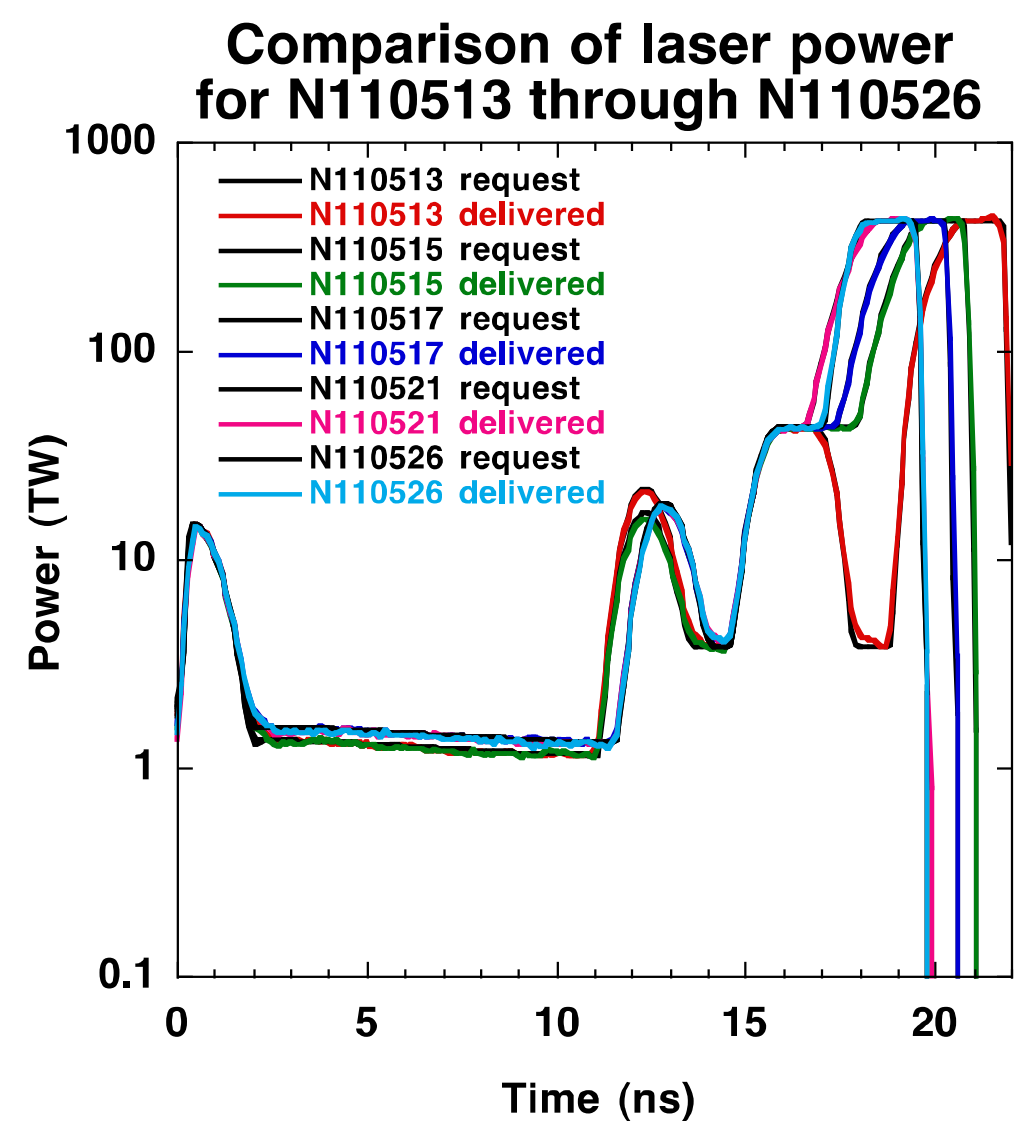

Figure 2. Comparison of the requested and delivered laser pulses used in the five shock timing experiments 
NIF-0117490

Table 1. List of shot-to-shot modifications to the pulse shape

\begin{tabular}{|c|c|c|c|c|c|}
\hline Shot & Picket & Trough & 2nd & $3^{\text {rd }}$ & 4th \\
\hline $\mathbf{N 1 1 0 5 1 3}$ & & & $+1 \mathrm{~ns}$ & $\begin{array}{c}\text { Added dip after } 3^{\text {rd }} \\
\text { delayed 2ns }\end{array}$ \\
\hline $\mathbf{N 1 1 0 5 1 5}$ & & & Decrease power 24\% & & $\begin{array}{c}\text { Remove dip after } 3^{\text {rd }} \\
\text { Advance launch } 1 \mathrm{~ns}\end{array}$ \\
\hline $\mathbf{N 1 1 0 5 1 7}$ & & $\begin{array}{c}\text { Increase } \\
\text { power } 15 \%\end{array}$ & $\begin{array}{c}\text { Increase power 12\%, } \\
\text { Delay launch 0.5ns }\end{array}$ & & Advance launch 0.5ns \\
\hline $\mathbf{N 1 1 0 5 2 1}$ & & & & & Advance launch 0.8ns \\
\hline $\mathbf{N 1 1 0 5 2 6}$ & & & & & Increase slope of $4^{\text {th }}$ rise \\
\hline
\end{tabular}

Figure 3 shows VISAR streak images for three of these shots. Time runs from left to right in each image, and lateral (top-to-bottom) motion of the interference fringes is proportional to the shock velocity, with fringe motion upward indicating an accelerating shock. The relatively darker fringes at the top and bottom of each image are reflections of the VISAR laser from the stationary Au aperture at the tip of the VISAR viewing cone. Fringe motion in between these stationary references is due to reflections from the leading shock front as viewed by the VISAR. Discontinuities in the fringe positions clearly indicate the arrival time of a shock. The first of these, labeled " 1 " and seen near 14 ns, is the time at which the $1^{\text {st }}$ shock breaks out of the ablator into the liquid deuterium. Subsequent discontinuities indicate the time at which the increasingly stronger $2^{\text {nd }}, 3^{\text {rd }}$, and $4^{\text {th }}$ shocks overtake or merge with preceding shocks. As is seen in Figure 3 , the interval between successive mergers is continually decreased to match the goal of having the $1^{\text {st }}$ three shocks merge at a single time (18.5 ns in Figure 3c).

The velocity of each shock is also very important. Figure 4(a) shows the velocity history for each of the shots. The velocity of the $1^{\text {st }}$ shock in both the ablator (before 14ns) and in the liquid deuterium (after $14 \mathrm{~ns}$ ) is very consistent from shot-to-shot. There is some variation in the time at which the shock breaks out from the ablator, which is due to variations in the ablator dimensions and the laser power in the early part of the pulse. Considerable variation is seen at the second shock level $(\sim 30 \mu \mathrm{m} / \mathrm{ns})$. These are due to the deterministic changes that were made to tune the second shock as seen in Table 1 . No changes were made to the $3^{\text {rd }}$ pulse power throughout the campaign, resulting is very consistent $3^{\text {rd }}$ shock velocities of $\sim 60 \mu \mathrm{m} / \mathrm{ns}$. The timing of the $4^{\text {th }}$ pulse was continually advanced through the campaign.

Figure 4(b) shows the shock trajectories in the liquid deuterium with $r=0$ being the ablator / deuterium interface. The positions of the mergers between shocks are indicated with the symbols. The goal is to have the merger of shocks $1-2$ and 2-3 positioned at $81 \mu \mathrm{m}$, which would put this triple-shock coalescence at a depth $5 \mu \mathrm{m}$ greater than the thickness of a DT ice layer in an ignition target. The goal for the shock 3-4 merger is slightly deeper at $97 \mu \mathrm{m}$. In the early shots, the merger positions were many tens of microns away from this goal, but as the campaign progressed, the merger positions were tuned to the goal with very high precision and acceptable repeatability. Note for shot N110526, the shock 1-2 and 2-3 mergers were at 81 and $84 \mu \mathrm{m}$, respectively, and the shock 3-4 merger was at $108 \mu \mathrm{m}$, all well within the requirements for this campaign. 
NIF-0117490

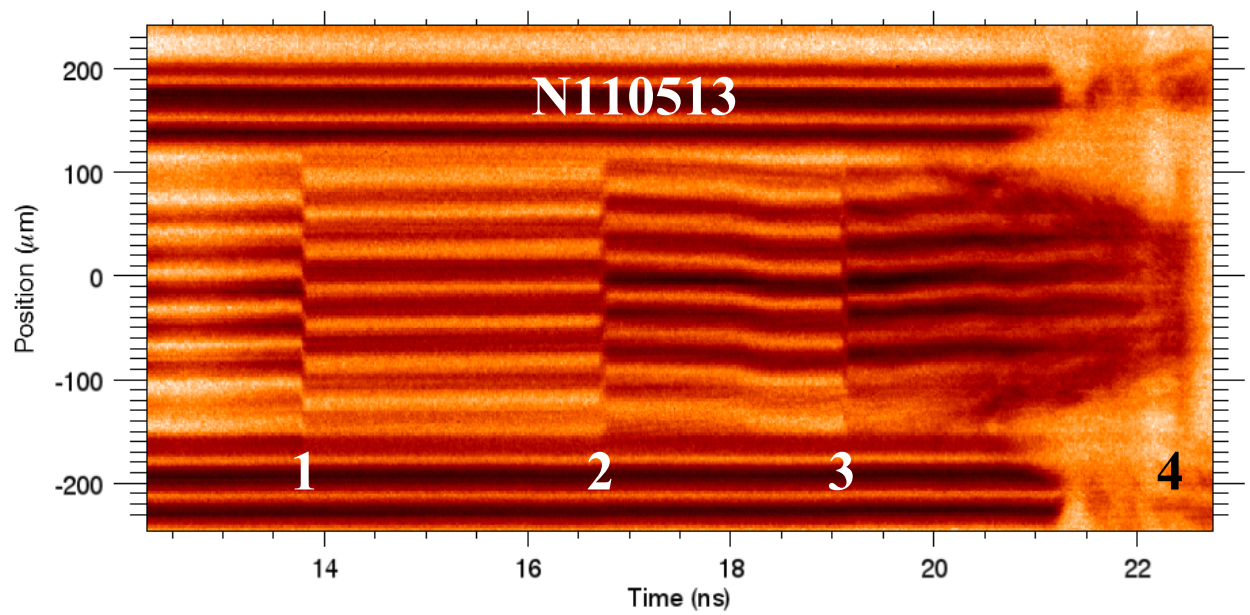

(a)

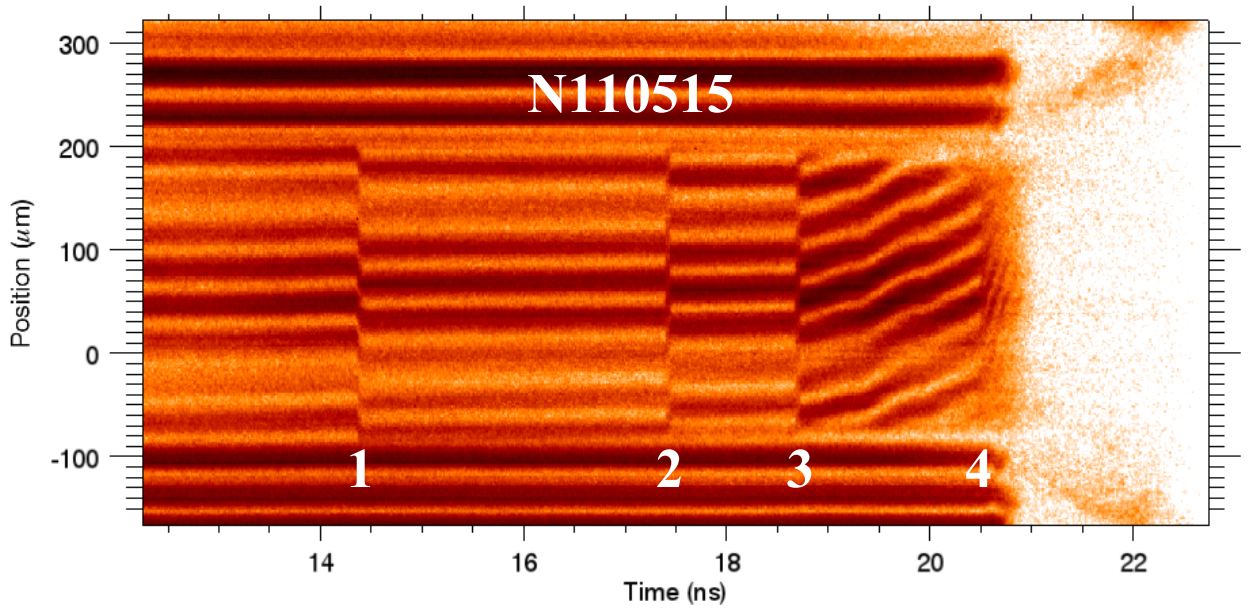

(b)

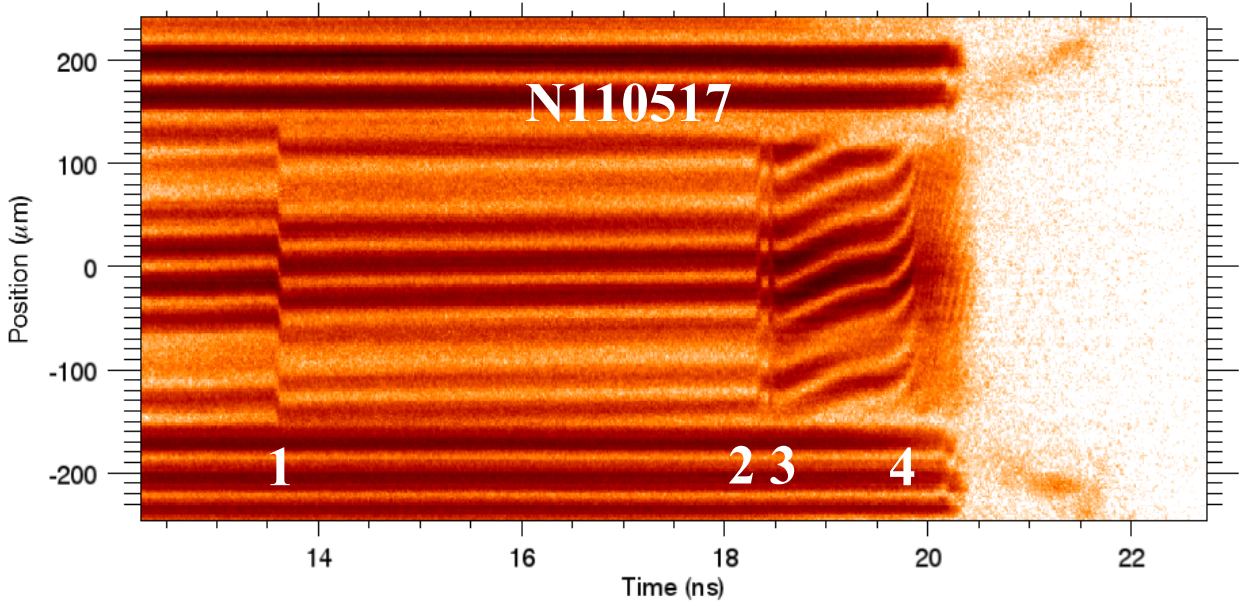

(c)

Figure 3. VISAR streak images for (a) N110513, (b) N110515, and (c) N110517 
NIF-0117490
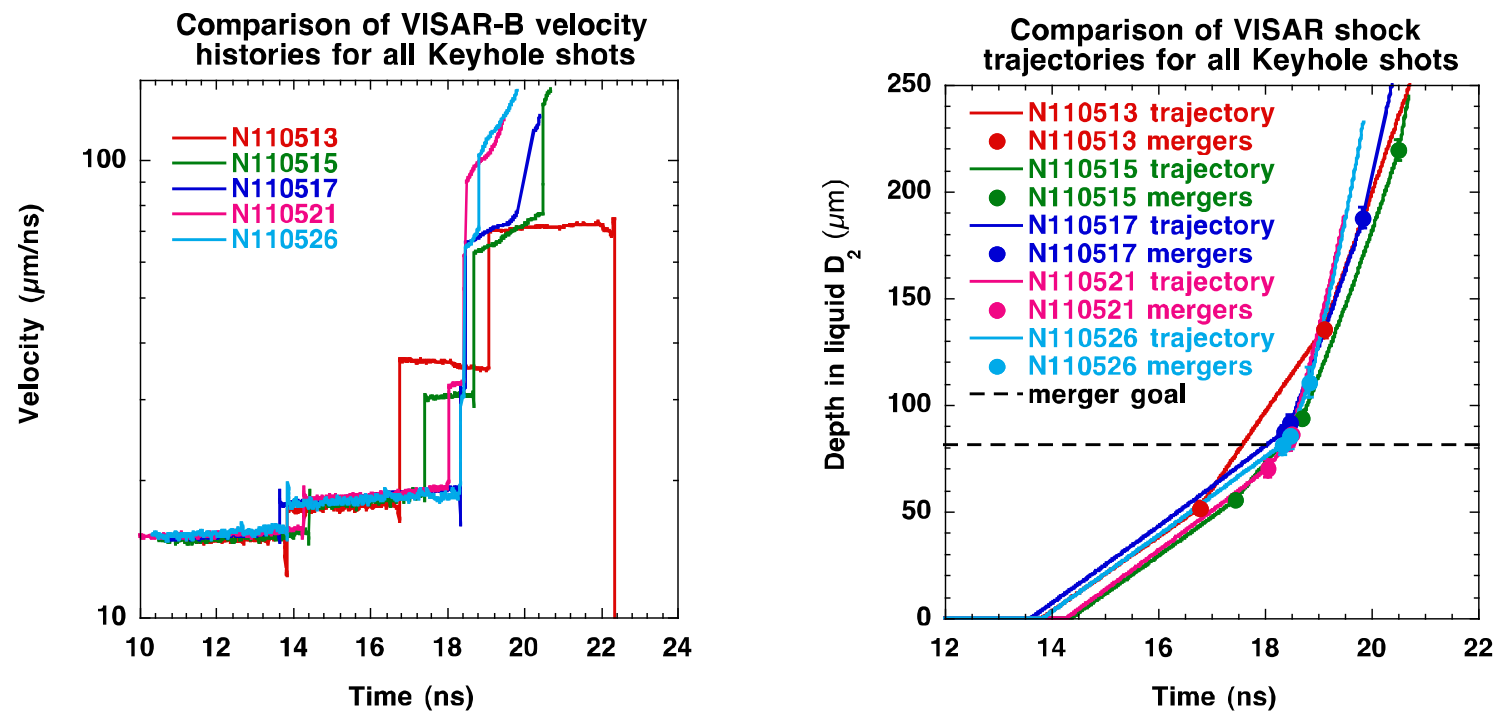

Figure 4. (a) VISAR velocity histories and (b) shock trajectories in liquid deuterium for each of the shots 